\title{
Age-related neuroinflammatory changes negatively impact on neuronal function
}

\author{
Marina A Lynch* \\ Trinity College Institute of Neuroscience, Trinity College, Dublin, Ireland
}

Edited by:

Thomas C. Foster, University of Florida, USA

\section{Reviewed by:}

Gary L. Wenk Ohio State University, USA

Thomas C. Foster, University of Florida, USA

\section{${ }^{*}$ Correspondence:}

Marina A Lynch, Neuroinflammation Research Group, Physiology, Trinity College Institute of Neuroscience, Trinity College, Dublin, Ireland. e-mail:Iynchma@tcd.ie
Neuroinflammatory changes, characterized by an increase in microglial activation and often accompanied by upregulation of inflammatory cytokines like interleukin-1 $\beta$ (IL-1 $\beta$ ), are common to many, if not all, neurodegenerative diseases. Similar, though less dramatic neuroinflammatory changes, are also known to occur with age. Among the consequences of these changes is an impairment in synaptic function and the evidence suggests that inflammatory cytokines may be the primary contributory factor responsible for the deficits in synaptic plasticity which have been identified in aged rodents. Specifically a decrease in the ability of aged rats to sustain long-term potentiation (LTP) in perforant path-granule cells of the hippocampus is associated with increased microglial activation. This review considers the evidence which suggests a causal relationship between these changes and the factors which contribute to the age-related microglial activation, and reflects on data which demonstrate that agents which inhibit microglial activation also improve ability of rats to sustain LTP.

Keywords: microglial activation, inflammatory cytokines, interleukin-1 $\beta$ (IL-1 $\beta$ ), long-term potentiation, neuroinflammation cell-cell interaction

\section{INTRODUCTION}

The brain has many unique immunological properties but it is not an immunologically-isolated organ (Akiyama et al., 2000). It differs from the periphery in that it is devoid of a lymphatic system to capture potential antigen, and expression of major histocompatability complexes I and II is very low in the normal brain indicating the lack of a professional antigen presentation system. A further specialization is that the entry of infiltrating cells, as well as larger molecules, are largely excluded by the blood brain barrier under normal conditions. However research in the past decade or two has led to the realization that the brain is exquisitely sensitive to inflammatory molecules and that the balance between pro- and anti-inflammatory influences in the microenvironment profoundly affects neuronal function.

It is now clear that neuroinflammation is a characteristic of many neurodegenerative disorders including Alzheimer's Disease (AD) and some authors, but by no means all, believe that chronic neuroinflammation may be an initiator in the cascade of events leading to the deficit in neuronal function which defines the disease. However even in the healthy brain, neuroinflammatory changes become evident as the individual ages and with the increase in the ageing population and the age-dependency of neurodegenerative disorders, there is a significant impetus to gain a greater understanding of the causes and consequences of the inflammatory changes that occur in the brain.

\section{MICROGLIA - THE IMMUNE CELLS OF THE BRAIN}

Microglia are the principal immune cells of the brain. Like macrophages, they are derived from bone marrow stem cells but become trapped in the CNS during early development. Under normal conditions, these cells adopt a ramified appearance and are in a so-called 'resting state'; their main role is surveillance of the microenvironment. Two major factors enable microglia to be maintained in the resting state. The first is the global absence of positive soluble stimulatory factors like interferon- $\gamma($ IFN $\gamma)$ which is present in significant concentrations only in times of stress or injury (Neumann, 2001). The second is the maintenance of cellcell interactions via ligand-receptor expression and binding, for example interaction between CD200 which is expressed on neurons and CD200 receptor, which is expressed on microglia (Hoek et al., 2000).

When stimulated, microglia undergo a morphological and functional transformation. There is a growing recognition that several subtypes of activated microglia exist (Perry et al., 2007; Lynch, 2009) but it is probably reasonable to broadly categorize activated microglia functionally into cells involved in antigen presentation, cells which variously release neurotrophins, chemokines, cytokines and reactive oxygen and nitrogen species, and cells which perform phagocytic functions. At this point, it is not possible to determine precisely how many intermediate states exist, nor to be confident that any or all of these states can co-exist. However what has become clear is that features of activated microglia have been identified in the brain of aged individuals while they are also characteristic of several neurodegenerative diseases and evident in brains of both aged animals (Lynch et al., 2007; Lyons et al., 2007a) and animal models of neurodegenerative diseases (McGeer and McGeer, 1998; Chen et al., 2005).

\section{WHAT INFLAMMATORY CHANGES HAVE BEEN IDENTIFIED IN THE AGED BRAIN? \\ EVIDENCE OF GLIAL ACTIVATION}

Microarray analysis of brain tissue prepared from young and aged rodents has demonstrated that of the genes which are upregulated with age, about half are associated with inflammation and oxidative 
stress (Prolla, 2002). In another study, upregulation of both MHCII and glial fibrillary acidic protein (GFAP) was reported in the brain of aged mice supporting the view that activation of microglia and astrocytes respectively are features of ageing (Godbout et al., 2005) and these findings are supported by evidence from immunohistochemical analysis and analysis of age-related changes in MHCII and GFAP mRNA (Lyons et al., 2009a).

MHCII interacts with $\mathrm{T}$ cell receptor provided costimulators CD80 and/or CD86 are also expressed on antigen-presenting cells like microglia, and it turns out that CD86 is increased in the hippocampus of aged rats accompanying the increase in MHCII and intercellular cell adhesion molecule (ICAM) expression (Griffin et al., 2006; Downer et al., 2010). Therefore it must be anticipated that, with age, increased interaction between $\mathrm{T}$ cells and microglia is likely to occur. With respect to the presence of $\mathrm{T}$ cells in the brain, it is widely accepted that cell numbers are low in the healthy brain, but that they increase dramatically in response to an immunological challenge (Hickey, 2001; Bailey et al., 2006). Passage of T cells into the brain is facilitated by the chemokine monocyte chemotactic protein-1 (MCP-1) acting in cooperation with another chemokine, macrophage inflammatory protein-1 (MIP-1 $\alpha$ ) (Aloisi et al., 2000) and the evidence shows that these chemokines are increased with age (Kumagai et al., 2007) and that there are age-related increases in both CD3 + lymphocytes and CD11c + dendritic cells in brain (Stichel and Luebbert, 2007).

\section{WHAT ARE THE CONSEQUENCES OF AN INTERACTION BETWEEN T CELLS AND MICROGLIA?}

In the last decade or so, it has become clear that interaction between $\mathrm{T}$ cells and microglia impacts on the activation state of both cell types. It was shown that T helper 1 (Th1) cells induced expression of MHCII, CD40, and CD54 on the surface of microglia, whereas Th2 cells failed to induce significant upregulation of these molecules (Aloisi et al., 1998, 2000). Th1 cells have also been shown to increase expression of CD80 on microglia (Wolf et al., 2001). On the other hand, microglia isolated from the CNS of mice were shown to induce production of IFN $\gamma$ and IL-2 by Th1 cells, while IFN $\gamma$, in turn, upregulated expression of MHCII, CD40, and CD54 (Aloisi et al., 2000). In addition to the age-related increase in expression of MHCII, CD80 and CD86, activated microglia express CD40, CD11b and molecules such as ICAM (Griffin et al., 2006; Lyons et al., 2009a) and binding of CD40 to its ligand, CD154, which is expressed primarily on activated $\mathrm{T}$ cells (Townsend et al., 2005) is also important in the interaction between microglia and $\mathrm{T}$ cells.

Recent work in this laboratory aimed to further investigate the consequences of interaction between microglia and T cells. In this case, amyloid- $\beta(A \beta)$-specific $T$ cells and myelin oligodendrocyte glycoprotein (MOG)-specific T cells were prepared and incubated in the presence of microglia prepared from transgenic mice which overexpressed amyloid precursor protein (APP) and presenilin-1 and MOG-treated mice (in which clinical symptoms of experimental autoimmune encephalomyelitis were demonstrated) respectively. The data indicated that Th1 cells markedly increased expression of cell surface markers on microglia and also increased production of inflammatory cytokines (Murphy et al., 2008; McQuillan et al., 2009).
These findings clearly indicate that the presence of Th1 cells in the brain exerts a significant effect on microglial activation and could potentially trigger a cascade of events leading to profound neuroinflammation.

\section{EXPRESSION OF CYTOKINES IS ALTERED IN THE BRAIN WITH AGE}

Activated microglia are considered to be the primary cell source of inflammatory cytokines like IL-1 $\beta$, IL- 6 and TNF $\alpha$, although astrocytes, when activated, also release these cytokines, particularly IL-6 (Li et al., 2009). The evidence suggests that reactive astrogliosis also occurs with age and a number of groups have reported that an age-related increase in GFAP (Kohama et al., 1995; Hayakawa et al., 2007). In parallel with glial activation, increases in these inflammatory cytokines have been reported in brain tissue obtained from aged rats and/or mice (Lynch and Lynch, 2002; Martin et al., 2002; Godbout and Johnson, 2004; Gelinas and McLaurin, 2005; Maher et al., 2005; Nolan et al., 2005; Campuzano et al., 2009). Age-related increases in concentration of other inflammatory cytokines have also been reported. For example IL-18, which is also released from activated microglia, is increased in hippocampal tissue prepared from aged, compared with young, rats (Griffin et al., 2006) and, like IL-1 $\beta$ and IL-6 (Griffin, 2006), its expression is increased in post-mortem brain tissue prepared from patients with $\mathrm{AD}$ (Ojala et al., 2009). IFN $\gamma$ concentration is also increased in the hippocampus with age but the cell course is unclear (see IFN $\gamma$ is a potent activator of microglia).

In aged rodents, the reported increase in hippocampal concentration of IL- $1 \beta$ is accompanied by a decrease in IL-4 (Maher et al., 2005; Lynch et al., 2007) and, similarly, the age-related increase in IL-6 (Ye and Johnson, 1999) is accompanied by a decrease in release of the anti-inflammatory cytokine IL-10 from brain slices (Ye and Johnson, 2001). While IL-10 suppresses synthesis of proinflammatory cytokines in brain (Strle et al., 2001), IL-4 decreases IL-1 $\beta$ mRNA synthesis and IL-1 $\beta$ release from glia (Loane et al., 2007; Lynch et al., 2007) and these findings, together with similar findings of others (Kitamura et al., 2000; Benveniste et al., 2004; Iribarren et al., 2005; Zhao et al., 2006), highlight the modulatory effect of anti-inflammatory cytokines on glial activation. The possibility therefore exists that the age-related decrease in concentration of anti-inflammatory cytokines may be the primary contributory factor in driving the age-related inflammatory phenotype.

\section{WHAT ARE THE CONSEQUENCES OF THESE NEUROINFLAMMMATORY CHANGES? INFLAMMATORY CHANGES PROFOUNDLY AFFECT BEHAVIOUR}

One of the important ramifications of an increase in inflammatory cytokines in the brain is that they profoundly affect behaviour. The effect of IL- $1 \beta$ on behaviour is most studied with multiple effects documented; it modulates exploratory behaviour, social exploration, social interaction and it also exerts a significant effect on the hypothalamic pituitary axis and therefore impacts on feeding and drinking behaviour and on sleep (Goshen and Yirmiya, 2009). It has been shown to specifically affect hippocampal-dependent learning. The first reported effect was in 1993 and, in this study, rats injected intracerebroventricularly with IL- $1 \beta$ exhibited poor performance in the Morris water maze (Oitzl et al., 1993). Further studies supported 
this finding with the observations that hippocampal-dependent tasks were also impaired when IL- $1 \beta$ concentration in hippocampus was increased following intraperitoneal injection or intrahippocampal injection of IL-1 $\beta$ (Gibertini et al., 1995; Barrientos et al., 2002), infection with Legionella Pneumophila (Gibertini et al., 1995) or, intracerebroventricular injection of Human Immunodeficiency Virus-1 envelope glycoprotein gp120 (Pugh et al., 2000). Injection of the gram-negative bacterial component lipopolysaccharide (LPS), has also been shown to affect spatial learning but, at least in the Morris water maze, there is the possible confound of the LPS-induced sickness behaviour which presents interpretative difficulties (Cunningham and Sanderson, 2008).

An important recent finding was that persistent overexpression of IL-1 $\beta$ in rat hippocampus (by activating the dormant human IL- $1 \beta$ excisional activation transgene (IL- $1 \beta^{\text {XAT }}$ ) had a detrimental effect on hippocampal-dependent learning; both contextual fear conditioning and behaviour in the Morris water maze were affected (Hein et al., 2009) and the negative impact on behaviour was accompanied by evidence of microglial activation, increased prostaglandin E2 and IL-1 $\beta$ concentrations and increased expression of the chemokines MCP-1 and MIP-1 (Moore et al., 2009). Interestingly chronic upregulation of IL- 6 by astrocytes is also associated with a progressive, age-related decline in avoidance learning, coupled with evidence of microglial activation (Heyser et al., 1997).

\section{Deficits in hippocampal-dependent behaviour in aged rats are linked with neuroinflammatory changes}

Many studies have demonstrated that spatial learning is decreased with age (Rapp and Gallagher, 1996; Rosenzweig and Barnes, 2003; Driscoll et al., 2006) and these changes have been linked with several age-related changes in hippocampal physiology, morphology and signalling. Recently it has been suggested that the age-related deficit in hippocampal-dependent learning is, at least in part, due to the age-related increase in IL-1 $\beta$ (Gemma and Bickford, 2007) and recent data from this laboratory has shown that the deficit in performance in the Morris water maze in aged rats, accompanied by a decrease in long-term potentiation (LTP), was associated with evidence of inflammation characterized by microglial activation.

\section{INFLAMMATORY CYTOKINES, WHICH ARE INCREASED WITH AGE, NEGATIVELY AFFECT LTP}

These data highlight the negative impact that inflammatory cytokines exert on synaptic plasticity and are mirrored by several reports of an inhibitory effect on LTP in vitro and in vivo. In vitro analysis has revealed that application of IL- $1 \beta$ inhibits LTP in CA1 (Bellinger et al., 1993; Ross et al., 2003), CA3 (Katsuki et al., 1990) and also in dentate gyrus (Cunningham et al., 1996). IL-18 has been classified as a member of the IL-1 family and, significantly, like IL$1 \beta$, IL-18 inhibits LTP; interestingly the effects of both IL- $1 \beta$ and IL-18 on LTP are inhibited by the endogenous IL-1 receptor antagonist, IL-1ra (Curran and O'Connor, 2001; Loscher et al., 2003). Both TNF $\alpha$ and IL- 6 have also been shown to inhibit LTP in vitro (Bellinger et al., 1995; Tancredi et al., 2000; Curran and O'Connor, 2003); indeed the inhibitory effect of A $\beta$ on LTP is reported to be TNF $\alpha$-mediated since slices prepared from mice deficient in TNF $\alpha$ were capable of sustaining LTP even in the presence of A $\beta$
(Wang et al., 2004). Further evidence of a negative impact of TNF $\alpha$ on LTP was recently obtained from this laboratory by the finding that intracerebroventricular injection of TNF $\alpha$ inhibited LTP in dentate gyrus while the deficit in LTP in aged rats was coupled with increased expression of TNF $\alpha$ in hippocampus.

Several experiments have also indicated that intracerebroventricular injection of IL-1 $\beta$ inhibits LTP in perforant path-granule cell synapses (Murray and Lynch 1998; Kelly et al., 2003; Nolan et al., 2005) while LTP is also attenuated when IL-1 $\beta$ concentration in hippocampus is increased by injection of LPS (Lonergan et al., 2004; Lynch et al., 2004; Barry et al., 2005) or A $\beta$ peptides (Lynch et al., 2007; Minogue et al., 2003, 2007). IL-1 $\beta$ concentration is also increased in brain tissue of animals following exposure to irradiation and this, too, is associated with decreased LTP (Lonergan et al., 2002; Lynch et al., 2003).

It is important to note that low concentrations IL- $1 \beta$ and IL-6 are likely to play a physiological function in LTP maintenance. Several studies have demonstrated that full expression of LTP is prevented in the absence of IL- $1 \beta$ or IL- 6 and, moreover, it has been reported that IL-1ra, which acts to prevent the action of IL-1 $\beta$, can block LTP (Schneider et al., 1998; Avital et al., 2003; Ross et al., 2003; Balschun et al., 2004).

\section{Deficits in LTP in aged rats are associated with neuroinflammatory changes}

Several studies have demonstrated that the ability of aged rats to sustain LTP is impaired in some way and, in an excellent review, Burke and Barnes exhaustively assessed some of the factors which contribute to this; whereas synaptic loss or loss of dendritic branching is largely unaffected with age, synaptic loss and synaptic restructuring are evident and, together with alterations in calcium handling by cells and gene expression, correlate with impairment in certain behaviours and in LTP (Burke and Barnes, 2006). However it has also been shown that the deficit in LTP in dentate gyrus in aged rats is positively correlated with IL- 4 concentration in the hippocampus and inversely correlated with hippocampal IL-1 $\beta$ concentration (Maher et al., 2005) and, while increased microglial activation is clearly evident in aged rats that fail to sustain LTP, this was not the case in aged rats which were capable of sustaining LTP (Maher et al., 2006). The negative impact of microglial activation on the ability of aged rats to sustain LTP is supported by the finding that minocycline, which inhibits microglial activation, at least partially restores LTP in aged rats (Griffin et al., 2006) and that IL-4, which reduces microglial activation, exerts a similar beneficial effect (Nolan et al., 2005). Indeed aged rats which received atorvastatin, rosiglitazone or the polyunsaturated fatty acid, eicosapentaenoic acid (EPA), were all capable of sustaining LTP compared with untreated aged rats and interestingly, the age-related microglial activation was attenuated by treatment in each of these cases, providing further evidence of a causative link between microglial activation and impaired LTP (Lynch et al., 2007; Clarke et al., 2008; Loane et al., 2009).

\section{WHAT SIGNALLING EVENTS ARE TRIGGERED BY INFLAMMATORY CYTOKINES?}

The functional receptor for IL- $1 \beta$ is IL- 1 type 1 receptor (IL-1R1) and its importance in driving neuroinflammatory changes in the brain has been clearly identified. Brain injury, for example a stab 
wound, induces profound microglial activation, infiltration of macrophages to the site of injury, and increased proinflammatory cytokine production but these responses are all decreased in IL-1R1-null mice (Basu et al., 2002) and the neuroinflammatory changes induced by hypoxic injury were similarly reduced in these mice (Basu et al., 2005). Activation of IL-1R1 leads to a myriad of responses; the first step involves protein:protein interactions and formation of a complex which includes adaptor proteins like MyD88, and the subsequent activation of IRAK. Further downstream, a complex which includes TRAF6 is formed triggering a sequence of steps that include phosphorylation of JNK and p38 and activation of transcription factors which include NFKB and c-jun. In the brain of aged rats, the reported increase in IL- $1 \beta$ is coupled with increased expression of IL-1R1 and with increased activation of IRAK1, JNK and p38 (Lynch and Lynch, 2002).

Understanding the mechanism by which IL-1 $\beta$ inhibits LTP has been approached by analysis of the effect of IL-1 $\beta$ on signalling events and by assessment of the modulatory effects of inhibitors. IL-1 $\beta$, and triggers like LPS and A $\beta$ which increase IL- $1 \beta$, have been shown to increase activation of JNK (Vereker et al., 2000a,b; Minogue et al., 2003) and, consistent with this, intracerebroventricular injection of the JNK inhibitor, D-JNKI1, ameliorates the inhibition of LTP induced by IL-1 $\beta$, LPS and A $\beta$ (Minogue et al., 2003; Barry et al., 2005) or amyloid- $\beta$ (A $\beta$ ) peptides (Minogue et al., 2003, 2007; Lynch et al., 2007). Similarly, application of the JNK inhibitor, SP600125, to slices blocked the IL-1 $\beta$-induced inhibition of LTP (Curran et al., 2003). A role for p38 has also been identified; thus IL-1 $\beta$ and LPS increase p38 activation and decrease LTP (Vereker et al., 2000b; Kelly et al., 2003), while treatment of rats with the p38 inhibitor, SB203580, attenuated the LPS-induced inhibition of LTP (Kelly et al., 2003). p38 activation has also been implicated in the inhibitory effect of TNF $\alpha$ on the early phase of LTP (Butler et al., 2004).

Although it simply provides circumstantial evidence, it has been shown that age-related activation of JNK and p38, which accompanies the deficit in LTP, are decreased in tissue prepared from aged rats treated with EPA (Martin et al., 2002). Similarly, when IL-1 $\beta$ - or LPS-induced inhibition of LTP is attenuated by EPA, or the anti-inflammatory cytokines IL- 4 or IL-10, or atorvastatin, then activation of the kinases, and indeed NFKB and c-jun, is reduced (Kelly et al., 2001; Lonergan et al., 2004; Lynch et al., 2004; Barry et al., 2005; Nolan et al., 2005; Clarke et al., 2008).

\section{THE AGE-RELATED NEUROINFLAMMATION SENSITIZES THE BRAIN TO INFLAMMATORY STIMULI}

Pre-existing underlying inflammation increases the vulnerability of aged rats to stressors. This has been consistently demonstrated in terms of responsiveness to LPS where exacerbation of microglial activation (particularly in terms of IL-1 $\beta$-immunoreactive microglia), sickness response (Godbout et al., 2005) and depressive behaviour (Godbout et al., 2008) has been reported. Ageing has also been shown to sensitize mice to the effects of E. Coli (Barrientos et al., 2006) and the HIV envelope protein, gp120 (Abraham et al., 2008); in both cases, behavioural effects were greater and more persistent in aged, compared with young, animals and the importance of IL-1 $\beta$ has been identified by the finding that the effect of E. coli infection was inhibited by IL-1ra (Frank et al. 2009).
We have also shown that implantation of IL- $1 \beta$-containing pellets which deliver the cytokine over a 4-week period, exerts a more profound inhibitory effect on LTP in dentate gyrus of 9-month old, compared with 3-month-old rats. Similarly, intracerebroventricular injection of $A \beta_{1-42}(20 \mu \mathrm{M})$, which was found to exert no substantial effect on expression of LTP in young rats, markedly decreased it in aged rats and this was accompanied by a more profound effect on IL-1 $\beta$ concentration in hippocampus of aged rats (Minogue et al., 2007).

\section{WHAT IS RESPONSIBLE FOR THE NEUROINFLAMMATORY CHANGES WHICH ACCOMPANY AGEING?}

While there is compelling evidence that microglial activation occurs with age, the factors which contribute to this change need to be clarified. A good starting point for consideration of this issue is the knowledge that in the intact healthy brain, the maintenance of microglia in their resting state is determined by the absence of stimulatory factors like IFN $\gamma$ and reduced interaction of microglia with other cells like neurons.

\section{IFN $\gamma$ IS A POTENT ACTIVATOR OF MICROGLIA}

IFN $\gamma$ is known to be one of the most potent activators of microglia (Benveniste et al., 2004) and, predictably, its expression is increased in the brain of aged animals (Maher et al., 2006; Moore et al., 2007; Clarke et al., 2008). Increased expression has also been reported in the brain of older wild-type (Wei et al., 2000) and Tg2575 (Abbas et al., 2002) mice, and in A $\beta$-treated rats in which microglia also adopt an activated phenotype (Minogue et al., 2007). The cell source of IFN $\gamma$ in the brain is not clear and we have been unable to show that it is released from microglia, although one group reported that IFN $\gamma$-immunoreactive CD11b-positive cells were observed in brain of severe combined immune-deficient mice following infection with Toxoplasma gondii (Suzuki et al., 2005). In the periphery, the primary cell source of is generally considered to be NK cells (Murasko and Jiang, 2005), although it is also released from Th1 cells, and recent evidence from this laboratory has identified the presence of NK cells in the brain, with an increase in cell number with age (Murphy and Lynch, 2009).

\section{INTERACTION OF MICROGLIA WITH OTHER CELLS AFFECTS ACTIVATION STATE}

Microglia interact with other cells which influence their activation state and reference has already been made to their interaction with $\mathrm{T}$ cells (see What are the consequences of an interaction between $\mathrm{T}$ cells and microglia?). However it has become clear in the past few years that they also interact with neurons with at least 2 pairs of ligands and receptors, fractalkine (also known as $\mathrm{CX}_{3}$ CL1) and its receptor, and CD200 and CD200 receptor, playing a part in maintenance of microglia in a quiescent state. Fractalkine is localized principally on neurons (Harrison et al., 1998) (Maciejewski-Lenoir et al., 1999), while the receptor is expressed chiefly on microglial cells (Harrison et al., 1998) and it has been shown that addition of soluble fractalkine, or neurons on which membrane-associated fractalkine is expressed, to LPS-stimulated microglia, markedly reduce their activation (Lyons et al., 2009a). Fractalkine expression is decreased with age and this is functionally associated with an increase in microglial activation and a decrease in the ability of 
aged rats to sustain LTP since intracerebroventricular injection of fractalkine attenuated both the age-related increase in microglial activation and the deficit in LTP (Lyons et al., 2009a).

A parallel situation occurs with CD200, in the sense that receptor expression is confined to cells of the myeloid lineage and therefore expressed in the brain only on microglia, while the ligand is widely expressed and found on neurons as well as numerous other cells (Barclay et al., 2002; Lyons et al., 2007a). Interaction of CD200 with its receptor plays a significant role in maintaining microglia in a quiescent state. Thus data from in vitro experiments have shown that addition of neurons to LPS- or A $\beta$-treated microglia decreases cell surface expression of activation markers and also decreases release of proinflammatory cytokines (Lyons et al., 2007a,b); these changes are blocked by an anti-CD200 antibody. We have recently shown that CD200Fc exerts a similar effect (Cox et al., 2009). Data from in vivo experiments have similarly identified the importance of CD200 ligand-receptor interaction in maintenance of microglia in a quiescent state; decreased CD200 expression, for example in aged rats and $A \beta$-treated rats is accompanied by increased microglial activation (Lyons et al., 2007a, 2009b) and we have recently shown that both the LPS- and age-related deficit in LTP are attenuated by intracerebroventricular injection of $\mathrm{CD} 200 \mathrm{Fc}$ (Cox et al., 2009). Consistent with these findings, $\mathrm{CD} 200^{-/-}$mice express an inflammatory phenotype, and we have recently established that glial cells prepared from $\mathrm{CD} 200^{-/-}$mice exhibit an exaggerated response to LPS with increased production and release of IL- $1 \beta$, IL- 6 and TNF $\alpha$ (Cox and Lynch, 2009). Analysis of LTP in hippocampal slices prepared from these mice revealed, first, that LTP was decreased compared with that obtained in slices from wild-type mice and, second, that LPS exerted a greater effect on LTP in slices prepared from $\mathrm{CD} 200^{---}$, compared with wild-type, mice.

\section{HOW CAN THE AGE-RELATED INFLAMMATORY CHANGES BE MODULATED? DOES THIS IMPACT ON FUNCTION?}

The data described above have indicated that the deficit in LTP induced by LPS can be rescued by $\mathrm{CD} 200 \mathrm{Fc}$ and, at least in this instance, the underlying action is to ameliorate the LPS-induced microglial activation by increasing CD200 receptor activation. Among the factors which increases expression of CD200 is IL-4 (Lyons et al., 2007a, 2009b) and, consistently, IL-4 has been shown to ameliorate the age-related impairment in LTP (Nolan et al., 2005) while it attenuates the A $\beta$-induced decrease in LTP (Lyons et al., 2007b) and reverses the associated decrease in CD200 (Lyons et al., 2009b). The negative impact of microglial activation on synaptic plasticity has been highlighted by the finding that treatment of aged rats with the inhibitor of microglial activation, minocycline, orally for 10 days partially attenuates the decrease in LTP (Griffin et al., 2006) while treatment of 12 -month-old mice which overexpress APP improved spatial learning (Fan et al., 2007).

A number of studies have provided further similar evidence indicating that agents which inhibit microglial activation have the capability of attenuating the deficits in LTP which occur in aged rats and/or in A $\beta$ and LPS-treated rats; these include the statin, atorvastatin (Clarke et al., 2007, 2008), a peptide which activates fibroblast growth factor receptor, FG loop, (Downer et al., 2010), rosiglitazone (Loane et al., 2009), and EPA (Minogue et al., 2007). In each of these situations, the evidence indicates that the deficit in LTP is accompanied by evidence of microglial activation and that treatment with the agent decreases microglial activation and restores LTP. Some groups have also used this approach to consolidate the coupling of microglial activation and deficits in behavioural tasks; for example it has been shown that antioxidants, including foods with antioxidant properties attenuate the age-related deficits in spatial learning (Youdim and Joseph, 2001) and also reduce microglial activation (Lau et al., 2007). Similarly $n-3$ polyunsaturated fatty acids, which have anti-inflammatory effects (Lynch et al., 2007) attenuate age-related deficits in spatial learning (Lim et al., 2005) and beneficial effects of curcumin have also been described (Frautschy et al., 2001). These data are useful in establishing parallels between microglial activation and synaptic plasticity with the significant limitation that they do not imply a causative interaction. It is important to recognize an additional limitation, i.e. that these data are based on a limited assessment of microglial activation, for example expression of cell surface markers of activation, or presumed microglial activation like inflammatory cytokine production. Accordingly while the circumstantial evidence suggesting the importance of microglial activation in inducing the age-related deficit in synaptic function is overwhelming, a more precise understanding of what is meant by the term 'microglial activation' is necessary, and a scientific approach which is more sophisticated than provision of correlational data is required, before there can be unequivocal acceptance of the causal relationship.

\section{REFERENCES}

Abbas, N., Bednar, I., Mix, E., Marie, S., Paterson, D., Ljungberg, A., Morris, C., Winblad, B., Nordberg, A., and Zhu, J. (2002). Up-regulation of the inflammatory cytokines IFN-gamma and IL-12 and down-regulation of IL-4 in cerebral cortex regions of APP(SWE) transgenic mice. J. Neuroimmunol. 126, 50-57.

Abraham, J., Jang, S., Godbout, J. P., Chen, J., Kelley, K. W., Dantzer, R. and Johnson, R.W. (2008). Aging sensitizes mice to behavioral deficits induced by central HIV-1 gp120. Neurobiol. Aging, 29, 614-621.
Akiyama, H., Barger, S., Barnum, S., Bradt, B., Bauer, J., Cole, G. M., Cooper, N. R., Eikelenboom, P., Emmerling, M., Fiebich, B. L., Finch, C. E., Frautschy, S., Griffin, W. S. Hampel, H., Hull, M., Landreth, G., Lue, L., Mrak, R., Mackenzie, I. R., McGeer, P. L., O'Banion, M. K., Pachter, J., Pasinetti, G., Plata-Salaman, C., Rogers, J., Rydel, R., Shen, Y. Streit, W., Strohmeyer, R., Tooyoma, I., Van Muiswinkel, F. L., Veerhuis, R., Walker, D. Webster, S., Wegrzyniak, B., Wenk, G., and WyssCoray, T. (2000). Inflammation and Alzheimer's disease. Neurobiol. Aging, 21, 383-421.
Aloisi,F.,DeSimone,R.,Columba-Cabezas, S., Penna, G., and Adorini, L. (2000). Functional maturation of adult mouse resting microglia into an APC is promoted by granulocyte-macrophage colony-stimulating factor and interaction with Th1 cells. J. Immunol. 164, 1705-1712.

Aloisi, F., Ria, F., Penna, G., and Adorini, L. (1998). Microglia are more efficient than astrocytes in antigen processing and in Th1 but not Th2 cell activation. J. Immunol. 160, 4671-4680.

Avital, A., Goshen, I., Kamsler, A., Segal, M., Iverfeldt, K., Richter-Levin, G., and Yirmiya, R. (2003). Impaired interleukin-1 signaling is associated with deficits in hippocampal memory processes and neural plasticity. Hippocampus 13, 826-834.

Bailey, S. L., Carpentier, P. A., McMahon, E. J., Begolka, W. S., and Miller, S. D. (2006). Innate and adaptive immune responses of the central nervous system. Crit. Rev. Immunol. 26, 149-188.

Balschun, D., Wetzel, W., Del Rey, A., Pitossi, F., Schneider, H., Zuschratter, W., and Besedovsky, H. O. (2004). Interleukin-6: a cytokine to forget. FASEB J. 18, 1788-1790.

Barclay, A. N., Wright, G. J., Brooke, G., and Brown, M. H. (2002). CD200 
and membrane protein interactions in the control of myeloid cells. Trends Immunol. 23, 285-290.

Barrientos, R. M., Higgins, E. A., Biedenkapp, J. C., Sprunger, D. B., Wright-Hardesty, K. J., Watkins, L. R., Rudy, J. W., and Maier, S. F. (2006). Peripheral infection and aging interact to impair hippocampal memory consolidation. Neurobiol. Aging 27, 723-732.

Barrientos, R. M., Higgins, E. A., Sprunger, D. B., Watkins, L. R., Rudy, J. W., and Maier, S. F. (2002). Memory for context is impaired by a post context exposure injection of interleukin-1 beta into dorsal hippocampus. Behav. Brain Res. 134, 291-298.

Barry, C.E., Nolan, Y., Clarke, R. M., Lynch, A., and Lynch, M. A. (2005). Activation of c-Jun-N-terminal kinase is critical in mediating lipopolysaccharideinduced changes in the rat hippocampus. J. Neurochem. 93, 221-231.

Basu, A., Krady, J. K., O’Malley, M., Styren, S. D., DeKosky, S. T., and Levison, S.W. (2002). The type 1 interleukin-1 receptor is essential for the efficient activation of microglia and the induction of multiple proinflammatory mediators in response to brain injury. J. Neurosci. 22, 6071-6082.

Basu, A., Lazovic, J., Krady, J. K., Mauger, D. T., Rothstein, R. P., Smith, M. B., and Levison, S. W. (2005). Interleukin1 and the interleukin-1 type 1 receptor are essential for the progressive neurodegeneration that ensues subsequent to a mild hypoxic/ischemic injury. $J$. Cereb. Blood Flow Metab. 25, 17-29.

Bellinger, F. P., Madamba, S., and Siggins, G. R. (1993). Interleukin 1 beta inhibits synaptic strength and long-term potentiation in the rat CA1 hippocampus. Brain Res. 628, 227-234.

Bellinger, F. P., Madamba, S. G., Campbell, I. L., and Siggins, G. R. (1995). Reduced long-term potentiation in the dentate gyrus of transgenic mice with cerebral overexpression of interleukin-6. Neurosci. Lett. 198, 95-98.

Benveniste, E. N., Nguyen, V. T., and Wesemann, D. R. (2004). Molecular regulation of CD40 gene expression in macrophages and microglia. Brain Behav. Immun. 18, 7-12.

Burke, S. N., and Barnes, C. A. (2006). Neural plasticity in the ageing brain. Nat. Rev. Neurosci. 7, 30-40.

Butler, M.P., O’Connor, J. J., and Moynagh, P. N. (2004). Dissection of tumornecrosis factor-alpha inhibition of long-term potentiation (LTP) reveals a p38 mitogen-activated protein kinase-dependent mechanism which maps to early-but not late-phase LTP. Neuroscience 124, 319-326.

Campuzano, O., Castillo-Ruiz, M. M., Acarin, L., Castellano, B., and
Gonzalez, B. (2009). Increased levels of proinflammatory cytokines in the aged rat brain attenuate injuryinduced cytokine response after excitotoxic damage. J. Neurosci. Res. 87, 2484-2497.

Chen, H., Jacobs, E., Schwarzschild, M. A., McCullough, M. L., Calle, E. E., Thun, M. J., and Ascherio, A. (2005). Nonsteroidal antiinflammatory drug use and the risk for Parkinson's disease. Ann. Neurol. 58, 963-967.

Clarke, R. M., Lyons, A., O’Connell, F., Deighan, B. F., Barry, C. E., Anyakoha, N. G., Nicolaou, A., and Lynch, M. A. (2008). A pivotal role for interleukin-4 in atorvastatin-associated neuroprotection in rat brain. J. Biol. Chem. 283, 1808-1817.

Clarke, R. M., O’Connell, F., Lyons, A., and Lynch, M. A. (2007). The HMGCoA reductase inhibitor, atorvastatin, attenuates the effects of acute administration of amyloid-beta142 in the rat hippocampus in vivo. Neuropharmacology 52, 136-145.

Cox, F. F., and Lynch, M. A. (2009). The lipopolysaccharide-induced increase in pro-inflammatory cytokine production is exaggerated in mixed glia prepared from mice deficient in CD200. Proc. Physiol. Soc. 15, PC14.

Cox, F. F., Miller, A. M., Lyons, A., and Lynch, M. A. (2009). A CD200 fusion protein attenuates LPS-induced changes in vivo and in vitro. Abstr. Soc. Neurosci. 545.8 .

Cunningham, A. J., Murray, C.A., O'Neill, L. A., Lynch, M. A., and O'Connor, J. J. (1996). Interleukin-1 beta (IL-1 beta) and tumour necrosis factor (TNF) inhibit long-term potentiation in the rat dentate gyrus in vitro. Neurosci. Lett. 203, 17-20.

Cunningham, C., and Sanderson, D. J. (2008). Malaise in the water maze: untangling the effects of LPS and ILlbeta on learning and memory. Brain Behav. Immun. 22, 1117-1127.

Curran, B., and O'Connor, J. J. (2001). The pro-inflammatory cytokine interleukin-18 impairs long-term potentiation and NMDA receptormediated transmission in the rat hippocampus in vitro. Neuroscience 108, 83-90.

Curran, B. P., Murray, H. J., and O'Connor, J. J. (2003). A role for c-Jun N-terminal kinase in the inhibition of long-term potentiation by interleukin-1beta and long-term depression in the rat dentate gyrus in vitro. Neuroscience 118 , 347-357.

Curran, B. P., and O'Connor, J. J. (2003). The inhibition of long-term potentiation in the rat dentate gyrus by proinflammatory cytokines is attenuated in the presence of nicotine. Neurosci. Lett. 344, 103-106.
Downer, E. J., Cowley, T. R., Lyons, A., Mills, K. H., Berezin, V., Bock, E., and Lynch, M. A. (2010). A novel antiinflammatory role of NCAM-derived mimetic peptide, FGL. Neurobiol. Aging 31, 118-128.

Driscoll, I., Howard, S. R., Stone, J. C., Monfils, M. H., Tomanek, B., Brooks, W. M., and Sutherland, R. J. (2006) The aging hippocampus: a multi-level analysis in the rat. Neuroscience 139, 1173-1185.

Fan, R., Xu, F., Previti, M. L., Davis, J., Grande, A.M., Robinson, J.K., and Van Nostrand, W. E. (2007). Minocycline reduces microglial activation and improves behavioral deficits in a transgenic model of cerebral microvascular amyloid. J. Neurosci. 27, 3057-3063.

Frank, M. G., Barrientos, R. M., Hein, A. M., Biedenkapp, J. C., Watkins, L. R., and Maier, S. F. (2009). IL-1RA blocks E. coli-induced suppression of Arc and long-term memory in aged $\mathrm{F} 344 \mathrm{xBN}$ F1 rats. Brain Behav. Immun. [Epub ahead of print].

Frautschy, S. A., Hu, W., Kim, P., Miller, S. A., Chu, T., Harris-White, M. E., and Cole, G. M. (2001). Phenolic antiinflammatory antioxidant reversal of Abeta-induced cognitive deficits and neuropathology. Neurobiol. Aging 22, 993-1005.

Gelinas, D. S., and McLaurin, J. (2005) PPAR-alpha expression inversely correlates with inflammatory cytokines IL-1beta and TNF-alpha in aging rats. Neurochem. Res. 30, 1369-1375.

Gemma, C., and Bickford, P. C. (2007) Interleukin-1beta and caspase-1: players in the regulation of age-related cognitive dysfunction. Rev. Neurosci. 18, 137-148.

Gibertini, M., Newton, C., Friedman, H., and Klein, T. W. (1995). Spatial learning impairment in mice infected with Legionella pneumophila or administered exogenous interleukin-1-beta. Brain Behav. Immun. 9, 113-128.

Godbout, J. P., Chen, J., Abraham, J., Richwine, A. F., Berg, B. M., Kelley, K. W., and Johnson, R. W. (2005). Exaggerated neuroinflammation and sickness behavior in aged mice following activation of the peripheral innate immune system. FASEB J. 19, 1329-1331.

Godbout, J. P., and Johnson, R. W. (2004) Interleukin-6 in the aging brain. J. Neuroimmunol. 147, 141-144.

Godbout, J. P., Moreau, M., Lestage, J., Chen, J., Sparkman, N. L., O' Connor, J., Castanon, N., Kelley, K. W., Dantzer, R., and Johnson, R. W. (2008). Aging exacerbates depressive-like behavior in mice in response to activation of the peripheral innate immune system. Neuropsychopharmacology 33, 2341-2351.
Goshen, I., and Yirmiya, R. (2009). Interleukin-1 (IL-1): a central regulator of stress responses. Front. Neuroendocrinol. 30, 30-45. [Epub ahead of print].

Griffin, R., Nally, R., Nolan, Y., McCartney, Y., Linden, J., and Lynch, M. A. (2006). The age-related attenuation in longterm potentiation is associated with microglial activation. J. Neurochem. 99, 1263-1272.

Griffin, W. S. (2006). Inflammation and neurodegenerative diseases. Am. J. Clin. Nutr. 83, 470S-474S.

Harrison, J. K., Jiang, Y., Chen, S., Xia, Y., Maciejewski, D., McNamara, R. K., Streit, W. J., Salafranca, M. N., Adhikari, S., Thompson, D. A., Botti, P., Bacon, K. B., and Feng, L. (1998). Role for neuronally derived fractalkine in mediating interactions between neurons and CX3CR1-expressing microglia. Proc. Natl. Acad. Sci. U.S.A. 95, 10896-10901.

Hayakawa, N., Kato, H., and Araki, T. (2007).Age-related changes of astorocytes, oligodendrocytes and microglia in the mouse hippocampal CA1 sector. Mech. Ageing Dev. 128, 311-316.

Hein, A. M., Stasko, M. R., Matousek, S. B., Scott-McKean, J. J., Maier, S. F., Olschowka, J. A., Costa, A. C., and O'Banion, M. K. (2009). Sustained hippocampal IL-1beta overexpression impairs contextual and spatial memory in transgenic mice. Brain Behav Immun. [Epub ahead of print].

Heyser, C. J., Masliah, E., Samimi, A., Campbell, I. L., and Gold, L. H. (1997). Progressive decline in avoidance learning paralleled by inflammatory neurodegeneration in transgenic mice expressing interleukin 6 in the brain. Proc. Natl. Acad. Sci. U.S.A. 94, 1500-1505.

Hickey, W. F. (2001). Basic principles of immunological surveillance of the normal central nervous system. Glia 36, 118-124.

Hoek, R. M., Ruuls, S. R., Murphy, C. A., Wright, G. J., Goddard, R., Zurawski, S. M., Blom, B., Homola, M. E., Streit, W. J., Brown, M. H., Barclay, A. N., and Sedgwick, J. D. (2000). Downregulation of the macrophage lineage through interaction with OX2 (CD200). Science 290, 1768-1771.

Iribarren, P., Zhou, Y., Hu, J., Le, Y., and Wang, J. M. (2005). Role of formyl peptide receptor-like 1 (FPRL1/FPR2) in mononuclear phagocyte responses in Alzheimer disease. Immunol. Res. 31, 165-176.

Katsuki, H., Nakai, S., Hirai, Y., Akaji, K., Kiso, Y., and Satoh, M. (1990). Interleukin-1 beta inhibits long-term potentiation in the CA3 region of mouse hippocampal slices. Eur. J. Pharmacol. 181, 323-326. 
Kelly, A., Lynch, A., Vereker, E., Nolan, Y., Queenan, P., Whittaker, E., O'Neill, L. A., and Lynch, M.A. (2001). The antiinflammatory cytokine, interleukin (IL)-10, blocks the inhibitory effect of IL-1 beta on long term potentiation. A role for JNK. J. Biol. Chem. 276, 45564-45572.

Kelly, A., Vereker, E., Nolan, Y., Brady, M., Barry, C., Loscher, C. E., Mills, K. H., and Lynch, M. A. (2003). Activation of p38 plays a pivotal role in the inhibitory effect of lipopolysaccharide and interleukin- 1 beta on long term potentiation in rat dentate gyrus. J. Biol. Chem. 278, 19453-19462.

Kitamura, Y., Taniguchi, T., Kimura, H., Nomura, Y., and Gebicke-Haerter, P. J. (2000). Interleukin-4-inhibited mRNA expression in mixed rat glial and in isolated microglial cultures. J. Neuroimmunol. 106, 95-104.

Kohama, S. G., Goss, J. R., Finch, C. E., and McNeill, T. H. (1995). Increases of glial fibrillary acidic protein in the aging female mouse brain. Neurobiol. Aging 16, 59-67.

Kumagai, N., Chiba, Y., Hosono, M., Fujii, M., Kawamura, N., Keino, H., Yoshikawa, K., Ishii, S., Saitoh, Y., Satoh, M., Shimada, A., and Hosokawa, M. (2007). Involvement of pro-inflammatory cytokines and microglia in an age-associated neurodegeneration model, the SAMP10 mouse. Brain Res. 1185, 75-85.

Lau, F. C., Bielinski, D. F., and Joseph, J.A. (2007). Inhibitory effects of blueberry extract on the production of inflammatory mediators in lipopolysaccharideactivated BV2 microglia. J. Neurosci. Res. 85, 1010-1017.

Li, X. Z., Bai, L. M., Yang, Y. P., Luo, W. F., Hu, W. D., Chen, J. P., Mao, C. J., and Liu, C. F. (2009). Effects of IL-6 secreted from astrocytes on the survival of dopaminergic neurons in lipopolysaccharide-induced inflammation. Neurosci. Res. 65, 252-258.

Lim, G. P., Calon, F., Morihara, T., Yang, F., Teter, B., Ubeda, O., Salem, N. Jr., Frautschy, S. A., and Cole, G. M. (2005). A diet enriched with the omega-3 fatty acid docosahexaenoic acid reduces amyloid burden in an aged Alzheimer mouse model. $J$. Neurosci. 25, 3032-3040.

Loane, D. J., Deighan, B. F., Clarke, R. M., Griffin, R. J., Lynch, A. M., and Lynch, M. A. (2007). Interleukin-4 mediates the neuroprotective effects of rosiglitazone in the aged brain. Neurobiol. Aging. 30, 920-931.

Loane, D. J., Deighan, B. F., Clarke, R. M., Griffin, R. J., Lynch, A. M., and Lynch, M. A. (2009). Interleukin-4 mediates the neuroprotective effects of rosiglitazone in the aged brain. Neurobiol. Aging 30, 920-931.
Lonergan, P. E., Martin, D. S., Horrobin, D. F., and Lynch, M. A. (2002). Neuroprotective effect of eicosapentaenoic acid in hippocampus of rats exposed to gamma-irradiation. J. Biol. Chem. 277, 20804-20811.

Lonergan, P. E., Martin, D. S., Horrobin, D. F., and Lynch, M. A. (2004). Neuroprotective actions of eicosapentaenoic acid on lipopolysaccharideinduced dysfunction in rat hippocampus. J. Neurochem. 91, 20-29.

Loscher, C. E., Mills, K. H., and Lynch, M. A. (2003). Interleukin-1 receptor antagonist exerts agonist activity in the hippocampus independent of the interleukin-1 type I receptor. $J$. Neuroimmunol. 137, 117-124.

Lynch, A. M., Loane, D. J., Minogue, A. M., Clarke, R. M., Kilroy, D., Nally, R. E., Roche, O. J., O'Connell, F., and Lynch, M. A. (2007). Eicosapentaenoic acid confers neuroprotection in the amyloid-beta challenged aged hippocampus. Neurobiol. Aging 28, 845-855.

Lynch, A. M., and Lynch, M. A. (2002). The age-related increase in IL-1 type I receptor in rat hippocampus is coupled with an increase in caspase- 3 activation. Eur. J. Neurosci. 15, 1779-1788.

Lynch, A. M., Moore, M., Craig, S., Lonergan, P. E., Martin, D. S., and Lynch, M. A. (2003). Analysis of interleukin-1 beta-induced cell signaling activation in rat hippocampus following exposure to gamma irradiation. Protective effect of eicosapentaenoic acid. J. Biol. Chem. 278, 51075-51084.

Lynch,A.M., Walsh,C., Delaney,A., Nolan, Y., Campbell, V. A., and Lynch, M. A. (2004). Lipopolysaccharide-induced increase in signalling in hippocampus is abrogated by IL-10-a role for IL-1 beta? J. Neurochem. 88, 635-646.

Lynch, M. A. (2009). The multifaceted profile of activated microglia. Mol. Neurobiol. 40, 139-156.

Lyons, A., Downer, E. J., Crotty, S., Nolan, Y. M., Mills, K. H., and Lynch, M. A. (2007a).CD200 ligand receptor interaction modulates microglial activation in vivo and in vitro: a role for IL-4. J. Neurosci. 27, 8309-8313.

Lyons, A., Griffin, R. J., Costelloe, C. E., Clarke, R. M., and Lynch, M. A. (2007b). IL-4 attenuates the neuroinflammation induced by amyloid-beta in vivo and in vitro. J. Neurochem. 101, 771-781.

Lyons, A., Lynch, A. M., Downer, E. J., Hanley, R., O'Sullivan, J. B., Smith, A., and Lynch, M. A. (2009a). Fractalkine-induced activation of the phosphatidylinositol-3 kinase pathway attentuates microglial activation in vivo and in vitro. J. Neurochem. 110, 1547-1556.
Lyons, A., McQuillan, K., Deighan, B. F., O'Reilly, J.A., Downer, E. J., Murphy, A. C., Watson, M.,Piazza,A.,O'Connell, F., Griffin, R., Mills, K. H., and Lynch, M. A. (2009b). Decreased neuronal CD200 expression in IL-4-deficient mice results in increased neuroinflammation in response to lipopolysaccharide. Brain Behav. Immun. 23, 1020-1027.

Maciejewski-Lenoir, D., Chen, S., Feng, L., Maki, R., and Bacon, K. B. (1999). Characterization of fractalkine in rat brain cells: migratory and activation signals for CX3CR-1-expressing microglia. J. Immunol. 163, 1628-1635.

Maher, F. O., Clarke, R. M., Kelly, A., Nally, R. E., and Lynch, M. A. (2006). Interaction between interferon gamma and insulin-like growth factor-1 in hippocampus impacts on the ability of rats to sustain long-term potentiation. J. Neurochem. 96, 1560-1571.

Maher, F. O., Nolan, Y., and Lynch, M. A. (2005). Downregulation of IL-4-induced signalling in hippocampus contributes to deficits in LTP in the aged rat. Neurobiol. Aging 26, 717-728.

Martin, D. S., Lonergan, P. E., Boland, B., Fogarty, M. P., Brady, M., Horrobin, D. F., Campbell, V. A., and Lynch, M. A. (2002). Apoptotic changes in the aged brain are triggered by interleukin-1beta-induced activation of $\mathrm{p} 38$ and reversed by treatment with eicosapentaenoic acid. J. Biol. Chem. 277, 34239-34246.

McGeer, E. G., and McGeer, P. L. (1998). The importance of inflammatory mechanisms in Alzheimer disease. Exp. Gerontol. 33, 371-378.

McQuillan, K., Lynch, M. A., and Mills, K. H. (2009). The role of T cell subtypes and their associated cytokines in modulation of amyloid-beta induced microglial activation. $J$. Neuroimmunol. 203, 195.

Minogue, A. M., Lynch, A. M., Loane, D. J., Herron, C.E., and Lynch, M.A. (2007). Modulation of amyloid-beta-induced and age-associated changes in rat hippocampus by eicosapentaenoic acid. $J$. Neurochem. 103, 914-926.

Minogue, A. M., Schmid, A. W., Fogarty, M. P., Moore, A. C., Campbell, V. A., Herron, C.E., and Lynch, M.A. (2003). Activation of the c-Jun N-terminal kinase signaling cascade mediates the effect of amyloid-beta on long term potentiation and cell death in hippocampus: a role for interleukin-1beta? J. Biol. Chem. 278, 27971-27980.

Moore, A. H., Wu, M., Shaftel, S. S., Graham, K. A., and O'Banion, M. K. (2009). Sustained expression of interleukin-1beta in mouse hippocampus impairs spatial memory. Neuroscience 164, 1484-1495.

Moore, M., Piazza, A., Nolan, Y., and Lynch, M. A. (2007). Treatment with dexamethasone and vitamin D3 attenuates neuroinflammatory age-related changes in rat hippocampus. Synapse $61,851-861$.

Murasko, D. M., and Jiang, J. (2005). Response of aged mice to primary virus infections. Immunol. Rev. 205, 285-296.

Murphy, A., Mills, K. H., and Lynch, M. A. (2009). Th17 cells induce microglial activation which is attenuated by neurons through CD200 ligand-receptor interactions. J. Neuroimmunol. 203, p209.

Murphy, K. J., and Lynch, M. A. (2009). Evidence that NK cells are present in the rat brain and have an age-related association with microglial activation. Proc. Physiol. Soc. 15, PC92.

Murray, C. A., and Lynch, M. A. (1998). Evidence that increased hippocampal expression of the cytokine interleukin1 beta is a common trigger for ageand stress-induced impairments in long-term potentiation. J. Neurosci. 18, 2974-2981.

Neumann, H. (2001). Control of glial immune function by neurons. Glia 36, 191-199.

Nolan, Y., Maher, F. O., Martin, D. S., Clarke, R. M., Brady, M. T., Bolton, A. E., Mills, K. H., and Lynch, M. A. (2005). Role of interleukin-4 in regulation of age-related inflammatory changes in the hippocampus. J. Biol. Chem. 280, 9354-9362.

Oitzl, M. S., van Oers, H., Schobitz, B., and de Kloet, E. R. (1993). Interleukin-1 beta, but not interleukin-6, impairs spatial navigation learning. Brain Res. 613, 160-163.

Ojala, J., Alafuzoff, I., Herukka, S. K., van Groen, T., Tanila, H., and Pirttila, T. (2009). Expression of interleukin-18 is increased in the brains of Alzheimer's disease patients. Neurobiol. Aging 30, 198-209.

Perry, V. H., Cunningham, C., and Holmes, C. (2007).Systemic infections and inflammation affect chronic neurodegeneration. Nat. Rev. Immunol. 7 , 161-167.

Prolla, T. A. (2002). DNA microarray analysis of the aging brain. Chem. Senses 27, 299-306.

Pugh, C. R., Johnson, J. D., Martin, D., Rudy, J. W., Maier, S. F., and Watkins, L. R. (2000). Human immunodeficiency virus-1 coat protein gp120 impairs contextual fear conditioning: a potential role in AIDS related learning and memory impairments. Brain Res. 861, 8-15.

Rapp, P. R., and Gallagher, M. (1996). Preserved neuron number in the hippocampus of aged rats with spatial learning deficits. Proc. Natl. Acad. Sci. U.S.A. 93, 9926-9930.

Rosenzweig, E. S., and Barnes, C.A. (2003). Impact of aging on hippocampal 
function: plasticity, network dynamics, and cognition. Prog. Neurobiol. 69, 143-179.

Ross, F. M., Allan, S. M., Rothwell, N. J., and Verkhratsky, A. (2003). A dual role for interleukin-1 in LTP in mouse hippocampal slices. J. Neuroimmunol. 144, 61-67.

Schneider, H., Pitossi, F., Balschun, D., Wagner, A., del Rey, A., and Besedovsky, H. O. (1998). A neuromodulatory role of interleukin-1beta in the hippocampus. Proc. Natl. Acad. Sci. U.S.A. 95, 7778-7783.

Stichel, C. C., and Luebbert, H. (2007). Inflammatory processes in the aging mouse brain: participation of dendritic cells and T-cells. Neurobiol. Aging 28, 1507-1521.

Strle, K., Zhou, J. H., Shen, W. H., Broussard, S. R., Johnson, R. W., Freund, G. G., Dantzer, R., and Kelley, K. W. (2001). Interleukin-10 in the brain. Crit. Rev. Immunol. 21, 427-449.

Suzuki, Y., Claflin, J., Wang, X., Lengi, A., and Kikuchi, T. (2005). Microglia and macrophages as innate producers of interferon-gamma in the brain following infection with Toxoplasma gondii. Int. J. Parasitol. 35, 83-90.
Tancredi, V., D’Antuono, M., Cafe, C., Giovedi, S., Bue, M. C., D'Arcangelo, G., Onofri, F., and Benfenati, F. (2000). The inhibitory effects of interleukin6 on synaptic plasticity in the rat hippocampus are associated with an inhibition of mitogen-activated protein kinase ERK. J. Neurochem. 75, 634-643.

Townsend, K. P., Town, T., Mori, T., Lue, L. F., Shytle, D., Sanberg, P. R., Morgan, D., Fernandez, F., Flavell, R. A., and Tan, J. (2005).CD40 signaling regulates innate and adaptive activation of microglia in response to amyloid beta-peptide. Eur. J. Immunol. 35, 901-910.

Vereker, E., Campbell, V., Roche, E., McEntee, E., and Lynch, M.A. (2000a). Lipopolysaccharide inhibits long term potentiation in the rat dentate gyrus by activating caspase-1. J. Biol. Chem. 275, 26252-26258.

Vereker, E., O’Donnell, E., and Lynch, M. A. (2000b). The inhibitory effect of interleukin-1beta on long-term potentiation is coupled with increased activity of stress-activated protein kinases. J. Neurosci. 20, 6811-6819.

Wang, Q., Rowan, M. J., and Anwyl, R. (2004). Beta-amyloid-mediated inhibition of NMDA receptor-dependent long-term potentiation induction involves activation of microglia and stimulation of inducible nitric oxide synthase and superoxide. J. Neurosci. 24, 6049-6056.

Wei, Y. P., Kita, M., Shinmura, K., Yan, X. Q., Fukuyama, R., Fushiki, S. and Imanishi, J. (2000). Expression of IFN-gamma in cerebrovascular endothelial cells from aged mice. $J$. Interferon Cytokine Res., 20, 403-409.

Wolf, S. A., Gimsa, U., Bechmann, I., and Nitsch, R. (2001). Differential expression of costimulatory molecules B7-1 and B7-2 on microglial cells induced by Th1 and Th2 cells in organotypic brain tissue. Glia 36, 414-420.

Ye, S. M., and Johnson, R. W. (1999). Increased interleukin- 6 expression by microglia from brain of aged mice. $J$. Neuroimmunol. 93, 139-148.

Ye, S. M., and Johnson, R. W. (2001). An age-related decline in interleukin10 may contribute to the increased expression of interleukin-6 in brain of aged mice. Neuroimmunomodulation 9, 183-192.

Youdim, K. A., and Joseph, J. A. (2001). A possible emerging role of phytochemicals in improving age-related neurological dysfunctions: a multiplicity of effects. Free Radic. Biol. Med. 30, 583-594.

Zhao,W., Xie, W., Xiao, Q., Beers, D. R., and Appel, S. H. (2006). Protective effects of an anti-inflammatory cytokine, interleukin-4, on motoneuron toxicity induced by activated microglia. $J$. Neurochem. 99, 1176-1187.

Conflict of Interest Statement: The author declares that the research was conducted in the absence of any commercial or financial relationships that could be construed as a potential conflict of interest.

Received: 24 November 2009; paper pending published: 02 December 2009; accepted: 08 December 2009; published online: 04 January 2010.

Citation:Lynch MA (2010)Age-related neuroinflammatory changes negatively impact on neuronal function. Front. Ag. Neurosci. 1:6. doi: 10.3389/neuro.24.006.2009 Copyright $\odot 2010$ Lynch. This is an openaccess article subject to an exclusive license agreement between the authors and the Frontiers Research Foundation, which permits unrestricted use, distribution, and reproduction in any medium, provided the original authors and source are credited. 